\title{
The Role of CAM (Complementary and Alternative Medicine): The Different Perspectives of Patients, Oncology Professionals and CAM Practitioners
}

\author{
Patricia Fox, Michelle Butler and Barbara Coughlan \\ UCD School of Nursing, Midwifery \& Health Systems, \\ University College Dublin, \\ Ireland
}

\section{Introduction}

The purpose of this chapter is to describe the different perspectives of women with breast cancer, oncology professionals and CAM practitioners regarding the role of $\mathrm{CAM}^{1}$ in the cancer setting. While all three stakeholder groups considered CAM as supportive, perspectives differed among oncology professionals and CAM practitioners regarding the manner in which this was so.

\subsection{Methods}

Semi-structured interviews were undertaken with 31 women with breast cancer, 20 oncology professionals (13 oncology nurses and 7 oncologists) and 20 CAM practitioners ${ }^{2}$. Interviews were analysed using a thematic networks technique (Attride-Stirling, 2001). Thematic analysis is the recognition of themes through a thorough reading and rereading of the transcripts (Ezzy, 2002, Liamputtong \& Ezzy, 2005). For this study, thematic analysis was supported by and presented as thematic networks: "web-like illustrations (networks) that summarize the main themes constituting a piece of text" (Attride-Stirling 2001, p. 386).

\footnotetext{
${ }^{1}$ The definition of CAM was based on definition advanced by the "Use of Complementary/ Alternative Therapies Survey" (UCATS) instrument (Lengacher et al., 2003) which was used in an earlier phase of this study to survey CAM use in 406 Irish women with breast cancer.

2 The CAM categories represented included TCM (Traditional Chinese Medicine), homeopathy, reflexology, massage therapy, counselling, nutritional therapy, and phytobiophysics. In the interest of maintaining confidentiality, the actual numbers representing each group are not identified. Most of the practitioners also had qualifications in other areas of CAM; however, the assigned titles reflect their primary specialty. Half the participants had a background in conventional medicine; eight were registered nurses and two were medical doctors. Two of the participants were cancer survivors. Five of the participants were based in CSCs, while the remaining practitioners worked in private practice.
} 


\section{The role of CAM in patients with cancer: The perspectives of women with breast cancer}

Of the 31 women interviewed, approximately $75 \%$ had used some form of relaxation and/or psychological therapy while $45 \%$ had used some form of biologically based therapy (health supplements, herbal supplements or antioxidants) for their breast cancer. Essentially, participants perceived that CAM can play a supportive role in the care of women with breast cancer by facilitating respite and psychological support while complementing conventional cancer treatment (see Figure 1.1). These three themes are discussed and corroborated in the following sections.

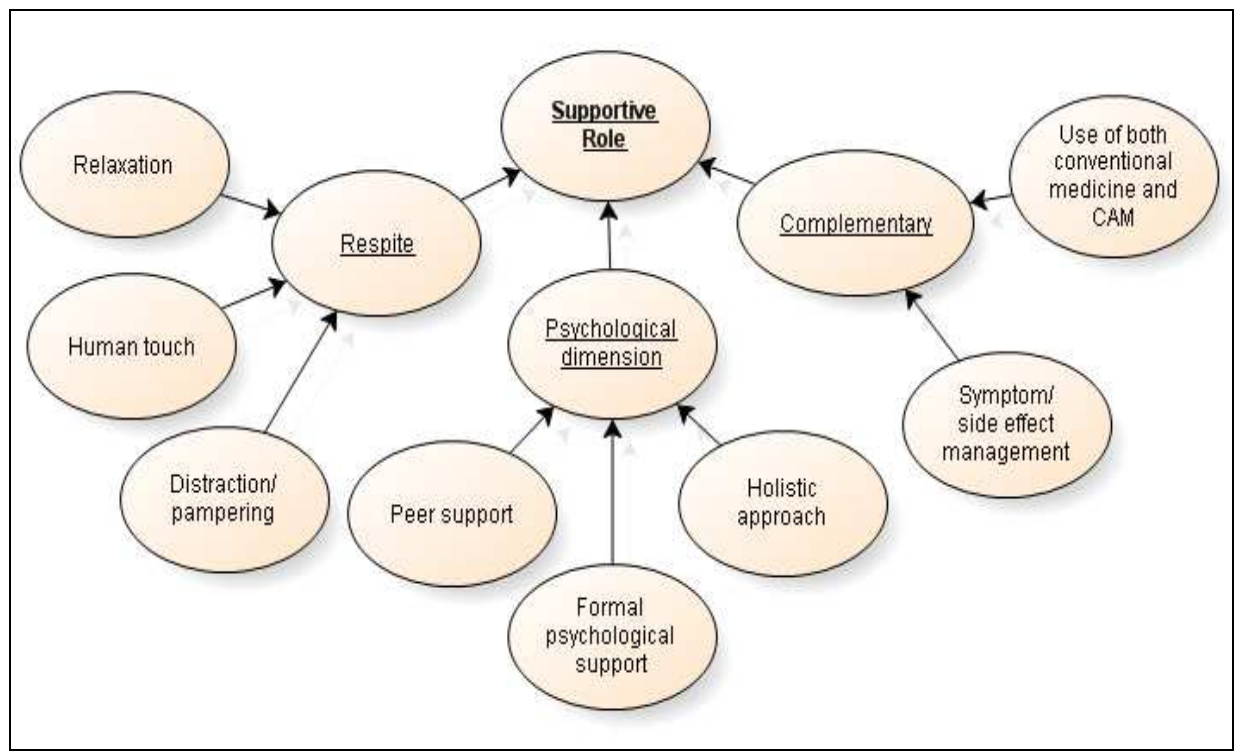

Fig. 1.1. The Supportive Role of CAM: perceptions of women with breast cancer

\subsection{Respite}

In terms of respite, participants underlined the importance of relaxation, human touch, distraction and pampering as they negotiated their cancer journey. The main therapies that were valued for inducing relaxation were massage, reflexology and yoga.

Participants discussed the value of different relaxation therapies to assist with coping and for stress reduction

Relaxation therapies were considered particularly valuable for newly diagnosed patients and for patients who had just had surgery.

... because it helps you get your head around it [cancer diagnosis] ... because when you are told your head is so full, it's so full (Participant 10)

... well I actually kind of relaxed a lot [following massage], ... you [are] uptight after the operation, naturally ... (Participant 18) 
For one participant, relaxation therapy was instrumental in enabling her to engage with the conventional treatment plan. Following her diagnosis, her anxiety level was such that it interfered with processing the important information imparted at the outset of treatment in relation to the anticipated effects and side effects of treatment. She stated that she was unable to concentrate or read the booklets given to her until she had had a "healing" massage done.

The benefits of relaxation therapies for dealing with stress were highlighted. One participant described herself as a relaxed person; however, she noted that she had become more anxious following her diagnosis and found that CAM therapies such as reflexology "were great at making me relax". Other therapies considered beneficial for alleviating stress included yoga and acupuncture.

In discussing CAM therapies that provided respite following their breast cancer diagnosis, some of the participants also noted the significance of human touch and there was a sense that it was associated with "healing".

... touch is very healing anyway and it's something about that close contact even for a half an hour ... I think all those things help people to heal (Participant 5)

For one participant, who described conventional treatment as "a living nightmare ... a living hell", CAM therapy and human touch clearly represented a respite from the treatment. Describing the Cancer Support Centre (CSC) as a "lovely space to be in", she stated that she availed of different hands-on therapies. Human touch in the form of massage was particularly significant for one participant who perceived that some people had an irrational fear of cancer. According to this participant, she sensed that certain people were afraid that if they touched her they would develop cancer.

Further evidence to support the concept of CAM as a form of respite comes from the references to distraction and pampering. One participant spoke about the value of introducing art therapy as a distraction into one of the chemotherapy day wards. A second participant had painted throughout her life and she acknowledged the distracting nature of the therapy following her cancer diagnosis. According to a third participant, the entire experience in the CSC was a positive one from the feeling of being pampered to the ambiance of the setting. For this participant, access to more therapies would have been appreciated.

... and again like that it was a beautiful room and lovely music and soft towels and soft pillows and to be pampered ... it's just ... I think that it is so important (Participant 3)

While another participant also referred to the pampering aspects of reflexology and massage, other more substantial outcomes such as improvements in sleep were also noted.

As outlined above, certain CAM therapies were embraced because they provided a diversion and a sense of pampering for some participants during their treatment. In summary, for women with breast cancer, the elements of CAM which contributed to a sense of respite included relaxation, human touch, and distraction/pampering. Participants' views on CAM from a psychological perspective are now examined. 


\subsection{Psychological dimension}

Fundamental to the perceived supportive role of CAM were its psychological dimensions. The psychological elements of CAM were central to coping for many participants and the merits of informal (peer support) and formal support (counselling/CBT) were highlighted in particular. Moreover, a holistic approach to care was appealing for some participants who highlighted the importance of treating both mind and body as they regarded physical and psychological states as being interdependent.

A number of the participants underlined the importance of meeting other women who were diagnosed with cancer and such meetings often took the form of support groups in the CSCs. According to the participants, the benefits included engaging with others who truly understood their situation having endured a similar experience, being able to discuss their disease openly without being fearful of engendering discomfort in others or worrying family members, and the provision of hope and practical advice. For one participant, being diagnosed with cancer was similar to grieving in that one needed "to have lost somebody to understand that horrible pain". She stated that she could not talk to her husband as he could not understand what she was going through when he did not have cancer himself.

... [patients] need to be with people [who] have had cancer to understand the pain and the anguish and the hurt ... like with like, they understand exactly ... (Participant 7)

This sense of a common bond was also described by other participants who attended support groups in the CSCs.

... there's a common bond there, it's like a member's only club ... (Participant 3)

One participant noted that it was liberating to be able to engage in an open and frank discussion about one's illness without feeling conscious of causing distress in others who do not have cancer and are therefore "quite afraid they might say the wrong thing". Other participants endeavored to protect their family and peer support enabled them to do so without having to compromise the expression of concerns for self. One participant also stated that while she initially discussed her illness with friends, as time went on she just said "I'm doing fine" because she did not want to be constantly talking about her health. She pointed to the "huge support" from her husband but noted that "there are still things that you can't say". While a second participant did discuss her illness with her family, she did not discuss it "in depth" so as not to worry them. Attending a support group and listening to another patient talk about life after her diagnosis many years before afforded some insight into life after diagnosis for one woman. She found it "unbelievable" that some patients had forgotten some details relating to their original diagnosis.

... it was incredible and at that stage I couldn't perceive a life ... but she [other patient] was talking about having a boat on $\mathrm{X}$ river ... (Participant 27)

For one younger participant, being linked in with other patients closer to her age was helpful on a practical level as it enabled her to discuss issues such as the cosmetic effects of treatment.

For some participants, formal psychological support in the form of counselling was central to their recovery as it also enabled participants to discuss their fears openly. Receiving practical tips and feeling listened to were particularly helpful for one participant as she was 
a young woman who was fearful that she would have a recurrence. She described how she had counselling in the CSC and also at another facility. If she had not had this counselling it would have made "the whole battle with the illness very, very difficult".

... just to be able to talk about you know your fears, your anxieties, what if my cancer has spread, what if I'm going to die, how will I deal with this ... (Participant 3)

One participant also noted the importance of being able to talk "out your fears" while for another counselling "helped me hugely". For another participant, counselling was so essential that it should be offered to all patients "immediately after the diagnosis". Moreover, this participant asserted that while the nurses were very supportive, it was necessary to have fully trained counsellors. Similar to views regarding the sense of ease experienced in discussing a cancer diagnosis with other cancer survivors, a key beneficial feature of counselling for one participant was the freedom from feeling she was going to cause "pain and hurt" to family and friends in the process. One participant relapsed fairly soon after her initial treatment and for this reason she actively sought out psychological support. She had counselling initially which she did not find helpful. Importantly, however, she was keen to avoid taking anti-depressants and went on to receive cognitive behavioural therapy (CBT) which she found "really, really helpful". One participant who did not attend a CSC had concerns about "reliving it again" rather than "putting it behind you". Of note, this participant did belong to a support group for another condition.

Consistent with the perspectives regarding the value of peer and formal psychological support noted previously, the importance of a holistic approach to care was highlighted by a number of women who had availed of CAM therapies. One participant gravitated towards Traditional Chinese Medicine (TCM) and homeopathy because the concept of looking at the "whole body" rather than being symptom focused appealed to her.

... I like homeopathy for the same reason, its, it's a whole body thing and symptoms are symptoms, they're not the first and only things that you look at (Participant 22)

For one participant, a holistic focus was wanting in one of the larger hospitals where she was treated. While acknowledging that she was medically well cared for, she was concerned that there was "no time for anything else"

... and you're not just a body you're a whole person so all of that is important you know like talking to people ... (Participant 14)

One participant contended that the tendency of CAM practitioners to listen and devote time to all of their patients concerns conveyed a sense of greater interest in patients, which for her was consistent with a more holistic approach in general. According to this participant, this approach contrasted with conventional hospitals which were focused on one aspect only. However, for two other participants, the provision of emotional support was not the responsibility of the medical staff as their duty is "the care of the patient and the medical side of it". While not overtly making reference to a holistic approach, other participants also pointed to the benefits of therapies which considered mind and body. According to one participant, mindfulness-integrated cognitive behaviour therapy (MiCBT) was "absolutely terrific" because it allowed one to access "what you're thinking, what you are feeling, physiologically". In addition, it was asserted that yoga meditation has an "extraordinary 
effect of relaxation" on the body and mind which "has to be therapeutic". For the same participant, the CSCs constituted a type of holistic refuge for patients who are recovering from their treatment and it was her contention that such Centres were "terrific really" for mind and body.

In summary, informal support in the form of cancer support groups clearly afforded a refuge for a number of the participants in their cancer journey in particular because they provided a facility whereby anxieties and fears could be openly expressed among peers. Additionally, formal psychological support in the form of counselling was credited with helping some participants cope with their illness. Counselling was also valued for reasons not dissimilar to those of peer support, that is, for enabling the discussion of concerns openly without feeling the need to hold back for the sake of others. In addition, for one participant who had relapsed, CBT was described as being very helpful. Finally, some of the participants articulated their interest in a holistic approach to care over the more specialty oriented approach of modern medicine. Consideration of the whole person addressing issues of both mind and body was considered desirable by a number of women who had availed of CAM therapies. For some of the participants, insufficient attention was directed toward a holistic approach in the larger conventional hospitals, while others did not see the provision of emotional support a necessary part of the doctors' role.

This section has provided evidence of the importance attributed to the psychological dimensions of CAM from the perspective of the participants who had availed of psychologically-based therapies. Finally, perceptions on the complementary nature of CAM are explored under the global theme of Supportive Role.

\subsection{Complementing conventional treatment}

Central to the notion that CAM plays a supportive role in the cancer setting was the perception that CAM is complementary to and therefore should operate in conjunction with conventional cancer treatment as opposed to instead of conventional treatment. The basic themes which provide support for this notion of CAM as "complementary" to conventional medicine include reports of patients' use of both conventional and CAM treatments and their use of CAM for symptom/side effect management as opposed to for curative intent.

Participants discussed their use both of conventional and CAM treatments and for some, integration of CAM and conventional treatment was a desirable goal.

I think working with both ... I don't think somebody should go over totally to alternative ... both together, but not one without the other ... (Participant 7)

One participant actively sought out herbal supplements for the treatment of hot flashes that resulted from conventional treatment as she wanted to avoid taking prescription medicine. For this participant also, it was important that conventional treatment and CAM should not be mutually exclusive. Another participant also spoke of her use of both systems. She sought out "natural remedies" but remained engaged with her conventional treatment. Similarly, for a third participant, CAM therapies were "just complementary ... it's not, a cure or anything like that". Of note, the idea of CAM being complementary is particularly 
exemplified in the case of one participant who did admit that historically she tended to gravitate more toward homeopathy and TCM rather than conventional medicine. However, when it came to treatment of her cancer she opted for conventional treatment as the primary treatment modality and used CAM as "an adjunct". This decision appeared to be motivated by a fear of the consequences that could result in forgoing conventional treatment. Likewise, although she had availed of CAM for other conditions, another participant also spoke of her fear of the consequences if she did not use conventional treatment for her breast cancer. She conceded that she preferred "to do other things" however, there appeared to be a paucity of information available regarding the efficacy of CAM in cancer treatment. Other participants expressed a desire for integration of CAM and conventional treatment with a view to combining "their skills and expertise" rather than "discount ... that whole spectrum of knowledge [in CAM]".

It is clear then that use of both systems (conventional and CAM) did feature for some participants following their cancer diagnosis. The importance of both conventional and CAM treatment was articulated. More specifically, there was a sense that conventional treatment should be the primary modality for treating cancer and it is likely that the lifethreatening nature of cancer may override the philosophical preferences of some individuals who may otherwise opt to avail of CAM. However, for some participants, there was a sense that a greater effort should be made to learn from ancient medical systems such as TCM. To further illustrate the point that CAM was used more to support participants through treatment than to treat the disease itself, use for symptoms/side effects is now discussed.

One participant described how she used TCM to "support my body to get through the chemo and the radiation". Homeopathy was used by another participant "for the sickness" while a third participant used it "to aid wound healing". One participant used a Bach flower remedy for anxiety when she was first diagnosed and later took an herbal supplement (black cohosh) for hot flashes. Other participants also noted the use of biologically based CAM therapies to alleviate the side effects of treatment induced menopause while Udo's Oil was used for joint stiffness which was attributed to an aromatase inhibitor. As outlined above, herbal and health food supplements were primarily used to alleviate and/or prevent side effects of conventional treatment. In essence, CAM was used to complement and support conventional treatment rather than to replace it. Of note, other participants were reluctant to take any herbal supplements while receiving conventional treatment; concern about interactions and the fact that they were already taking enough medications were the reasons advanced for this position.

The purpose of this section was to identify the role of CAM in the cancer setting as perceived by women with breast cancer. Notwithstanding the complex nature of CAM, and drawing on the various themes emerging from the data, in the main, women with breast cancer perceived CAM as playing a supportive role in the cancer setting. The evidence for this conclusion is derived from the perceived importance of CAM in terms of respite and psychological care tempered with the recognition that that conventional treatment should be the primary modality for cancer treatment. Having elicited the perspectives of women with breast cancer regarding the role of CAM in the cancer setting, the perceptions of oncology professionals are now explored. 


\section{The role of CAM in patients with cancer: The perspectives of oncology professionals}

Oncology professionals perceived CAM use along a continuum in relation to the inherent benefits and risks of the therapies and whether or not they should be used in addition to or instead of conventional treatment. Therapies such as relaxation treatments and psychological support occupied one end of this continuum; according to all of the participants, there is a role for these therapies in the management of patients with cancer. More specifically, participants recognised a role for CAM therapies in providing support for patients on their cancer journey. Other CAM therapies which were used as a substitute for conventional treatment were at the opposite end of the continuum and considerable concern was expressed with respect to these therapies. Finally, certain approaches such as biologically based CAM therapies and acupuncture occupied a more intermediate position on the continuum and a more guarded approach was adopted in relation to these therapies; however, this was context-sensitive, for example, certain therapies were considered acceptable in some circumstances but not in others. The themes that emerged in interviews with oncology professionals (Figure 1.2) are explored in more detail in the following sections.

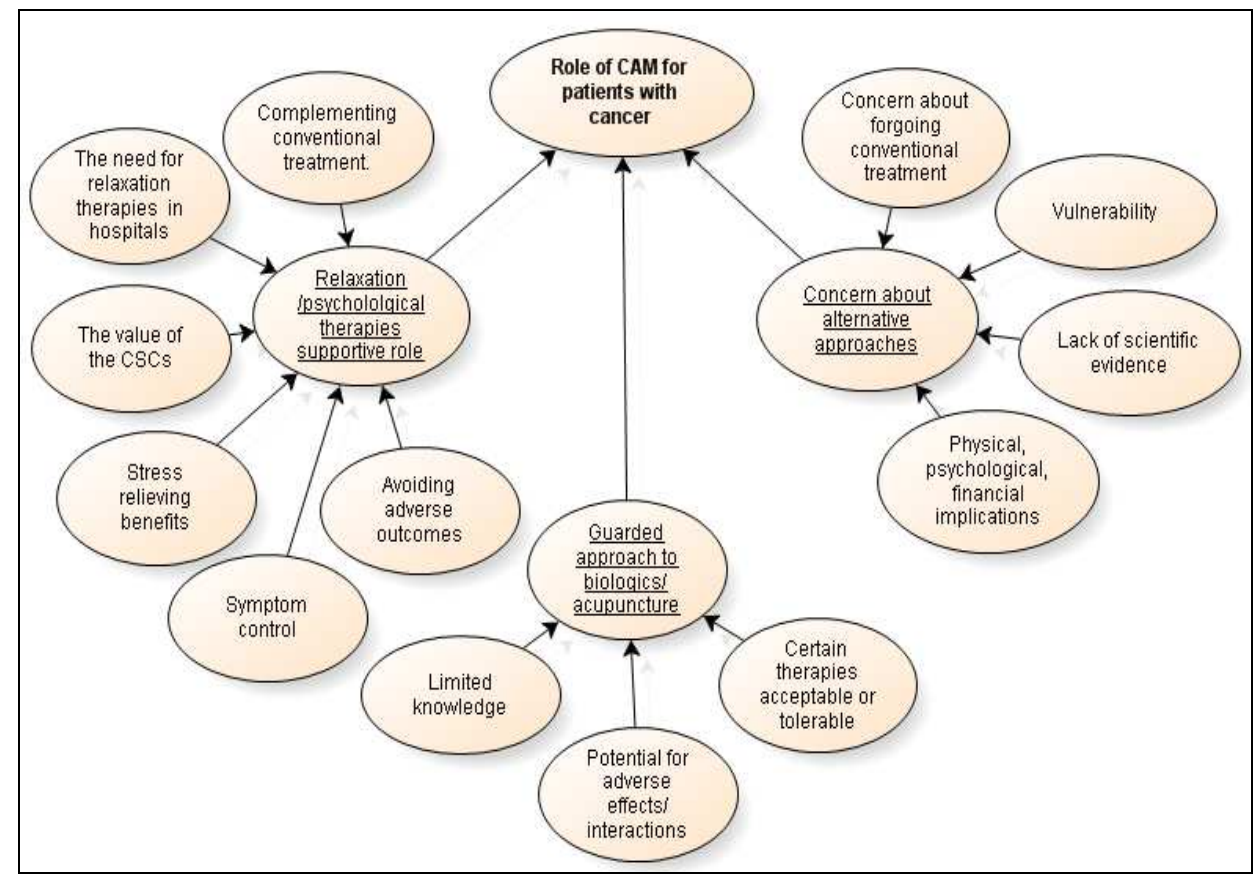

Fig. 1.2. Oncology professionals' perceptions of the role of CAM in patients with cancer

\subsection{The role of relaxation/psychological-based therapies}

There was a perception that relaxation and psychological therapies were important in terms of the supportive role they provide for patients with cancer. In discussing the supportive role of these therapies, oncology professionals discussed this type of CAM in relation to stress relief 
and such therapies were perceived as being complementary to conventional treatment. The need for more relaxation therapies in hospitals was noted; however, the value of the CSCs was clearly articulated. Although, primarily valued for their psychological benefits, relaxation therapies were also considered to benefit patients physically in some cases. While participants mainly discussed the value of relaxation/psychological based therapies, they also sounded a note of caution with respect to the potential for adverse effects.

The importance of relaxation therapies for relieving stress was highlighted with some participants placing particular emphasis on this issue for young women with families. According to one of the nurses, young women with breast cancer benefit in particular from relaxation therapies as they are dealing with the stress of the illness while trying to cope with other personal and family concerns. Another nurse also noted the "very stressful time" for young women juggling their treatments with caring for children and "school runs, all this carry on". Her endorsement of massage and reflexology was based on the positive feedback from patients on this type of CAM. According to another nurse, yoga and reiki are used by "a lot of patients" who appear to benefit from their distracting effects describing them as "a brilliant switch off mechanism" which "takes them away from the reality of the situation for a while".

In helping patients to cope with the stress of the illness and treatment, relaxation therapies were essentially seen as complementing conventional treatment.

... that they would still have the conventional treatment, the treatment that is recommended and have other treatments in conjunction with it (RN)

According to another participant, patients should be able to access any such therapies if they consider they may be helpful as long as they continue with "the general medicine". The oncologists were similarly positively disposed to relaxation/psychologically based CAM therapies as long as patients continued with their conventional treatment. Acknowledging the benefits of relaxation therapies, one of the oncologists had participated in the introduction of relaxation therapies into a hospital abroad and was investigating a similar initiative in his current workplace. While some of the nurses made reference to having a staff member in the hospital that came around on certain days, there was an interest in having a more consistent provision of CAM in the oncology day wards where patients attended for chemotherapy. For one of the nurses, this was based on her experience of having a CAM practitioner on site when she worked abroad. This participant noted that it would be beneficial to have access to massage therapists and reflexologists in her current institution to alleviate the stress for patients who were about to have their treatment. It was contended that such an approach may obviate the need to administer anxiolytics to anxious patients as is currently the practice. This notion of having certain CAM therapies available in the hospital setting was articulated by other nurses. It was maintained that such an initiative would lessen the burden for patients in terms of avoiding the inconvenience of having to go elsewhere for these therapies because they "have enough to cope with". The financial implications associated with accessing relaxation therapies privately were also noted given that patients have a lot of additional expenses because of their illness. Given that CAM services were limited or non-existent in the hospitals where the participants were based, the patients were primarily advised to attend the CSCs to avail of CAM therapies. 
Although some of the participants articulated the importance of having relaxation therapies available through the hospitals, the value of the CSCs was highlighted by all of the participants. All of the nurses indicated that they encouraged patients to attend the CSCs in order to avail of those services. The tendency to recommend patients to attend the CSCs appeared to be based on the notion that they were in safe hands.

... and I suppose we all also kind of just use the safeguard 'oh go up to X CSC' (RN)

While the relaxation therapies were considered beneficial in their own right to assist with coping, the value of the extra time that accompanied some of the therapies was also noted. According to another nurse, there were "huge psychological benefits" for patients who attended the CSCs, not least because they were given "time" and were "surrounded in a non-threatening way" by knowledgeable people. Some of the therapies provided at the centres were "hugely beneficial" in assisting some patients to "get through what was a rough time" according to another nurse.

While the therapies provided in the CSCs may have some physical benefits in terms of relaxing patients or alleviating pain and/or nausea, their primary role was the provision of psychological support.

... and they may have some knock on physical effect ... but the main benefit is to help people cope psychologically with the illness (MO)

As noted, there was a perception that the benefits of relaxation/psychological therapies were primarily related to their psychological effects, however; there was also a sense that there may be benefits in terms of symptom control albeit to a lesser degree. Some of the nurses perceived that relaxation therapies such as reflexology and massage were helpful in inducing rest and sleep for patients.

In terms of restfulness and trying to sleep, I would find that they find that helps them in that respect $(\mathrm{RN})$

Massage and yoga were also considered to be beneficial for shoulder stiffness in women recovering from breast surgery which involved axillary lymph node dissection and one nurse advised her patients to visit the nearby CSC for yoga for this reason.

While there was consensus that relaxation and psychologically based CAM therapies had an important role to play for patients with cancer and were unlikely to be harmful, participants highlighted the potential for adverse outcomes in some cases. Some of the participants articulated the importance of ensuring that CAM providers possessed the requisite qualifications in order to safeguard against such adverse outcomes. Moreover, for other participants, if patients were to attend CAM practitioners outside the hospital, it was "very important" that those practitioners would have taken some formal training in treating patients with cancer and that they would be registered.

... or have done a course maybe in relation to the cancer patient (RN)

The importance of "careful selection" and "assessment" was also highlighted in order to guide patients to the therapies that may be of most benefit such as to appropriate support groups.

It is apparent then that participants were confident that relaxation/psychological therapies play an important supportive role for patients with cancer. While there was agreement 
regarding the supportive role of relaxation/psychological therapies in the cancer setting, a more guarded approach was adopted with regard to other CAM therapies and this is now discussed.

\subsection{Guarded approach to biologically based therapies and acupuncture used in conjunction with conventional treatment}

Participants were more guarded in their response to the use of biologically based therapies (health-food/herbal supplements, special anti-cancer diets) and acupuncture used in conjunction with conventional treatment. This was primarily due to limited knowledge regarding the nature of these therapies, and concern about their potential for adverse effects and interactions (with respect to supplements). This notwithstanding, not all therapies in this category were considered equal in terms of risk; in some cases, therapies were considered harmless and possibly even beneficial. In other cases, participants articulated their concerns about certain therapies but adopted a somewhat tolerant approach to their use while other therapies were considered to be problematic particularly during active conventional treatment and patients were strongly advised to avoid such therapies during that time. Of note, participants' concerns regarding some therapies were context-sensitive, that is to say, therapies that were a cause for concern in certain circumstances were considered acceptable or even beneficial in other circumstances.

Most of the participants interviewed were hesitant about herbal supplements pointing to their limited knowledge regarding the nature of this type of CAM. Highlighting the paucity of information and research available on herbal supplements, one nurse stated that when asked about herbal supplements she would advise patients to take a multivitamin only.

... I'm not knowledgeable enough about it ... there's not enough information or research out there ... $(\mathrm{RN})$

Limited knowledge about the nature of herbal supplements also deterred another nurse from recommending herbal supplements because "we don't know exactly what's in them". In addition to herbal supplements, in some instances anti-cancer diets were not recommended because of insufficient knowledge about them. In certain cases, where concerns existed among nurses about the nature and safety of supplements, patients' queries were referred to the oncologists. In contrast to relaxation/psychological therapies, participants appeared much less inclined to recommend biologically based therapies and there was no mention of acupuncture being recommended to patients.

One of the primary reasons for the adoption of a guarded approach to certain oral CAM therapies was concern about the potential for adverse effects and interactions with conventional treatment. Participants also expressed some general concerns about biologically based therapies regardless of the context. These concerns had to do with the potential for adverse effects relating to issues of quality control. Adulteration of herbal supplements with medications such as anticoagulants was identified as a serious issue and concern was also expressed about the potential for contamination.

... and Chinese medicines are notorious for actually having quite a lot of actual ingredients including things like steroids and goodness knows what ... (MO) 
For example, Chinese herbal medicines which ... are often made in vats of lead ... (MO)

Another participant noted that an unnecessary diagnostic procedure was almost performed on a patient who appeared jaundiced as a result of taking carotene supplements. Some of the oncologists also expressed concerns about the possibility of misdiagnosis if patients attended a CAM practitioner for symptom management rather than following up with the oncologist. Reservations in this context were primarily based on the likelihood of harm from recurrent or progressive disease being misdiagnosed and/or exacerbated. Osteopathy fell into this category due to concern about manipulation where there may be disease recurrence. There were similar concerns about patients with undiagnosed bone metastases seeking acupuncture for pain relief.

... that they haven't told the doctor about and that you end up with them having a pathological fracture [which] could have been treated with one single fraction of radiotherapy ... (MO)

Patients on conventional treatment were also advised against acupuncture primarily because of concerns about infection while they were immunosuppressed. In this case, concern was context-sensitive. Apart from avoiding acupuncture during immunosuppression, one oncologist who was not opposed to the therapy per se noted that it was very much on the "borderline" and practised by some GPs in the present day. Nurses' concerns about acupuncture were similarly related to the potential for complications during immunosuppression.

In addition to potential adverse effects of CAM therapies, participants were concerned about interactions with conventional treatment, particularly in relation to herbal supplements. Concerns about interactions with conventional treatment related primarily to chemotherapy; however, potential for interaction with radiotherapy was also considered.

I know there's been another case report of radiation interaction with herbal and things you know ... (MO)

Mindful of the safety implications, one oncologist asked patients to write out a list of all medications and supplements that they may be taking.

... because if somebody has an unexpected reaction to the chemotherapy, we don't know is it because they've just started taking giant hog weed extract ... (MO)

Unease was also expressed by some of the nurses with regard to the potential for drug/herb interactions. In some cases, nurses simply advised patients against taking any herbal supplements. Potential for interactions between herbal supplements and general prescription medications was also highlighted by a participant who cited the case of a patient who experienced weight loss when taking kelp while on Thyroxine.

These concerns notwithstanding, some biologically based CAM therapies were considered to be harmless and possibly even beneficial. Based on their experience, two of the nurses considered the benefits of ginger in alleviating nausea. Other supplements such as linseed and Evening Primrose Oil were also considered for their potential to alleviate menopausal symptoms. One of the oncologists indicated that he was not concerned about a lot of the supplements that patients were taking as he perceived such supplements to be harmless. As noted, other CAM therapies such as acupuncture were also considered acceptable as long as 
patients were not immunosuppressed. One of the oncologists suggested it would be reasonable to think about acupuncture for pain control where mainstream treatments were found to be ineffective.

Participants' views in relation to the use of some biologically based therapies also depended on the context and they were tolerated so long as there was no risk of them being taken at a time when they could interfere with conventional treatments. Participants appeared considerably more concerned about anti-cancer diets and some herbal remedies; however, there appeared to be an acceptance among participants that use of such therapies may have psychological benefits for the patients taking them. One nurse recalled her experience of caring for a patient who was undergoing conventional treatment but also taking a strict anticancer diet. Conscious of the obvious weight loss, this nurse expressed concern to the patient about her minimal food intake.

... and she [patient] said 'I've two young kids, its my only chance', she [said], 'this is what gets me through my day' she [said] 'when I crave for something to eat' (RN)

This nurse acknowledged that the patient appeared to benefit psychologically from this measure and admitted that if she was told she had a life-threatening illness herself it is likely that she would also explore all options. While acknowledging that it may also be diseaserelated, another participant spoke of her own distress on witnessing a "very sick" patient lose a significant amount of weight while on a restrictive anti-cancer diet during the palliative stage of his illness. There was recognition again that hope was the driving force behind this approach which was being encouraged by the patient's wife. Similarly, there appeared to be a degree of internal conflict for another nurse as she grappled with supporting a patient in his endeavors although she was unconvinced about the herbal supplement he was taking. According to this participant, it was particularly "difficult" because the patient frequently asked the nurses for their views on the supplement in question. Unease was also expressed by other nurses about the potential for some biologically based CAM therapies to induce nausea in patients; however, they did not appear to actively dissuade patients from taking these therapies. One nurse expressed such disquiet with respect to some of the "herbal concoctions" taken. However, again there appeared to be an attempt to strike a balance between facilitating hope and avoiding harm. Likewise, one of the oncologists asserted that he did not actively attempt to dissuade his patients from taking certain biologically based therapies. For this oncologist, there was "no point arguing about it" as patients benefited psychologically from assuming some control over their health in this manner.

As noted then, while participants had concerns about certain CAM therapies on a number of levels, not all therapies were considered equal in terms of risk. Moreover, the contextsensitive nature of some concerns added to the complexity of the situation. Participants were considerably more wary about other CAM therapies which were perceived to be harmful for various reasons and these are discussed in the next section.

\subsection{Concern regarding more alternative approaches}

Participants articulated considerable concern regarding the use of alternative approaches which may be substituted for conventional treatment. In addition, participants discussed 
issues such as vulnerability, lack of scientific evidence and the physical, psychological and financial implications of using such therapies.

Considerable concern was expressed about patients who forgo conventional cancer treatment for alternative treatments. However, it was acknowledged that this represented a very small proportion of patients and that the trend appeared to be downward.

I have seen patients pursuing alternative therapies run into serious trouble and die ... when they have refused standard care and, and ... gone an alternative route (MO)

One nurse was apprehensive about patients seeking alternative treatment on the basis of her experience with one young patient. This patient had a potentially curable colorectal cancer and subsequently developed metastatic disease having opted to undergo alternative treatment instead of chemotherapy. According to this participant, the patient had travelled to another country to receive the alternative treatment and had discontinued her conventional treatment.

In discussing their concerns about patients attending alternative practitioners, the vast majority of the oncologists alluded to the vulnerable position of patients with cancer. Pointing to patients who are exposed to the "charlatan cure" on the Internet, one oncologist stated that he encourages his patients to bring along any such information that they may wish to discuss.

... I emphasise that 'you are vulnerable, don't waste your money; these people are charlatans and you've got to be careful' (MO)

The primary concern was that in their vulnerable state, patients were open to all possibilities for treating their cancer including "unproven" treatments. The use of anecdotal reports rather than scientific evidence to promote certain treatments was identified as a particular problem and was highlighted by all of the oncologists. Perceiving that they were being deceived, one oncologist endeavoured to dissuade his patients from attending alternative practitioners who were offering treatments based on "anecdotal responses".

In discussing the issue of a lack of scientific evidence associated with certain treatments, one oncologist spoke of the importance of conducting randomized controlled trials (RCTs) to evaluate conventional treatments adding that similar "ethics" do not apply for the "charlatan cure". Some of the oncologists were "open-minded" about certain CAM therapies such as TCM; however, according to one, any use of these therapies in the future would need to employ scientific methods. Similarly, there was a suggestion that if scientific methods were employed to explore the nature of herbal supplements, they may have a role in the future. Although somewhat less vocal about the lack of scientific merit, the importance of a scientific approach to evaluating CAM therapies was also important for some of the nurses.

... but maybe some sort of scientific clinical trial; evidence might make people swing a little bit more towards it (RN)

While forgoing conventional treatment appeared to be of primary concern for participants, there was also considerable unease with regard to adverse effects resulting from the use of some CAM therapies regardless of whether they were used in addition to or instead of conventional treatment. One of the oncologists explicitly advised his patients against some therapies. 
... any of the more vigorous or ... intensive approaches like enemas and that type of thing, obviously I don't condone and, and advise against (MO)

One of the nurses considered a possible adverse effect from a psychological perspective in that she perceived that some patients who opted for alternative treatment may agonize over the prudence of their decision. She recalled the case of one patient who subsequently appeared more "irritable" having chosen alternative treatment instead of chemotherapy. Concern was also expressed about the cost to patients in terms of "time". There was a perception that time spent pursuing some CAM therapies was a waste of the "limited" time that was left for patients who were in the palliative stage of illness. One of the oncologists referred to patients who travel to countries such as Mexico for "unproven treatments" as an example of this.

... spend ... the limited time that they have they spend it away from their family on a wild goose chase and I think that's where it has an negative impact (MO)

Participants also considered adverse effects in terms of financial implications for patients who were availing of certain types of CAM. One of the oncologists endeavored to caution his patients against spending large amounts of money and patients' vulnerability was again highlighted. Other participants also expressed their concerns about the "major cost implications" for their patients.

The person was administering completely unproven therapies to patients and charging them a fortune (MO)

Some of the nurses were also robust in their criticism of certain practitioners who were treating patients with cancer outside of the conventional setting and taking "mega money" from them.

... I've huge concerns [about] people not in a hospital setting putting up IVs [intravenous infusions] what are they putting up in them, absolutely, I think they should be arrested (RN)

The costs of travel alone were highlighted as in the case of one patient with advanced disease who was considering travelling to a faith healer in Brazil. According to the participant, the patient was paying thousands of Euros simply juts to travel there.

As outlined, oncology professionals expressed considerable concern about therapies that were used as a substitute for conventional cancer treatment. It is likely that participants were particularly emphatic in their opposition to these therapies due to their perception that patients were adversely affecting their chances of survival and/or control of cancer by forgoing scientifically tested treatments for treatments that have not been put through such rigorous tests. Adding to their concern was the fact that patients were vulnerable and that in addition to the health implications there may also be financial implications for patients in this context.

In summary then, participants' attitudes to CAM are a reflection of the complexity of the subject. Certain CAM therapies such as relaxation and psychological therapies were perceived as having an important supportive role in the care of patients with cancer. Conversely, alternative therapies did not have any place in the cancer setting while other biologically based therapies/acupuncture were seen to occupy a more intermediate position with participants adopting a guarded approach to these therapies. 


\section{The role of CAM in patients with cancer: The perspectives of CAM practitioners}

In the main, CAM was perceived by CAM practitioners as providing a supportive role for patients with cancer (Figure 1.3). According to the CAM practitioners, a holistic approach was adopted in order to assist the patients in their cancer journey. The primary emphasis was on addressing patients' physical (symptom/side effects) and psychological needs although the importance of "mental" and spiritual concerns was also underlined by some participants. Participants also described CAM as being complementary to conventional treatment although there were different perspectives in this regard.

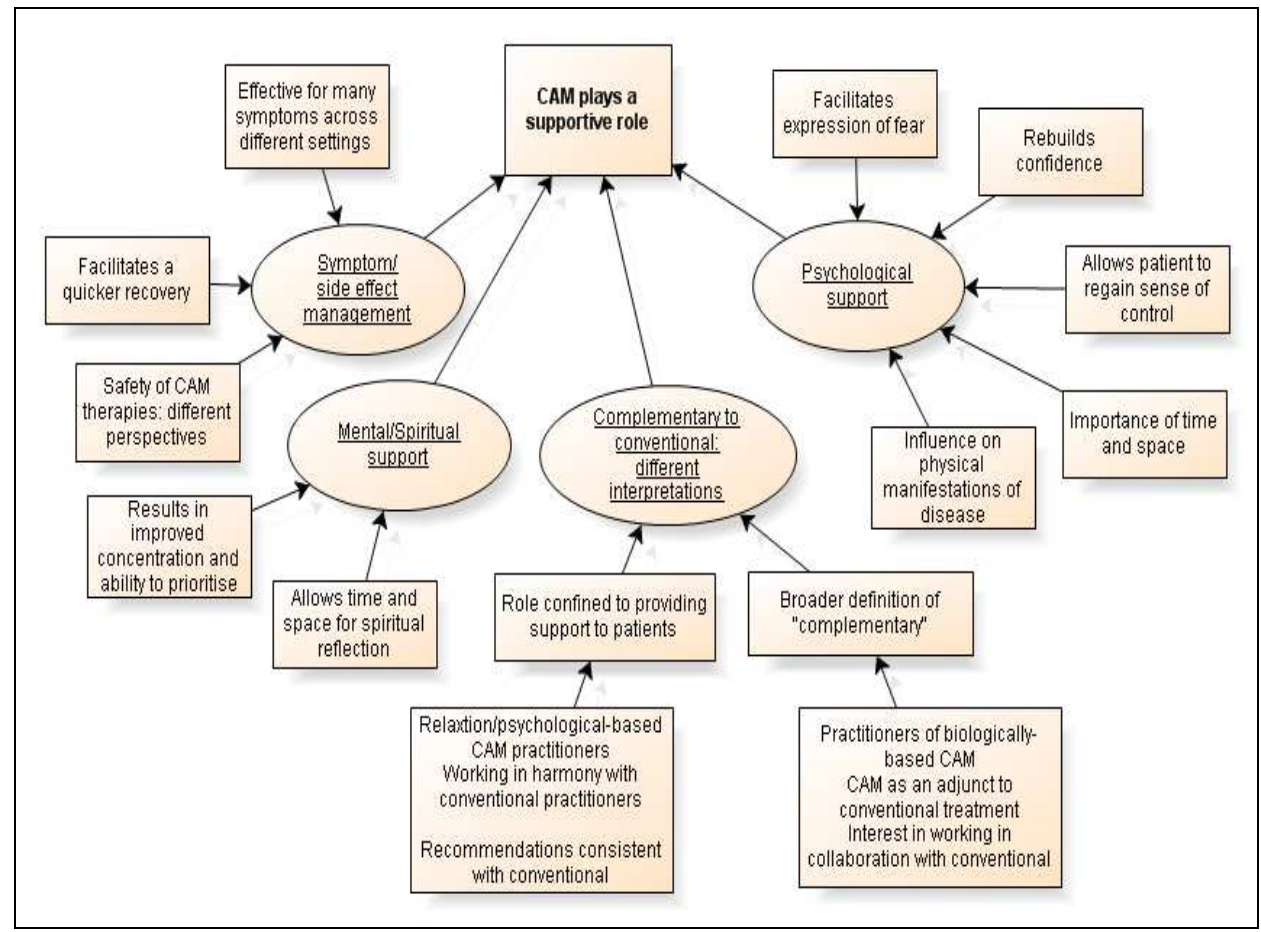

Fig. 1.3. CAM practitioners' perceptions of the role of CAM in patients with cancer

\subsection{Symptom/side effect management}

Although they employed different CAM therapies, all of the CAM practitioners identified the value of CAM for alleviating patients' symptoms and the side effects of conventional treatment. According to the participants, CAM facilitates a quicker recovery from side effects of conventional treatment, and it is effective for many side effects across different settings, however there were different perspectives regarding the safety of certain CAM therapies.

The TCM practitioners perceived an important role for CAM in addressing the side effects of conventional treatment. For some, CAM enabled a quicker recovery for patients. 
... so that their bodies can recover maybe more quickly after they've had their chemo or radiation with less side effects (TCM).

While acknowledging the role of conventional medicine in cancer treatment, another TCM practitioner highlighted the value of CAM in strengthening patients following this treatment. According to this practitioner, patients who have received herbal medicine while undergoing chemotherapy recover more quickly than those who have not received herbal medicine.

Chinese medicine comes in, and keeps their body strong, builds their blood, their white cell count up, keeps them from vomiting ... (TCM)

Similarly, for another TCM practitioner, CAM had a role in strengthening the patients' immune system following conventional treatment which "biomedicine cancer treatment overwhelms". Another participant identified a role for phytobiophysics in addressing bone marrow suppression following chemotherapy and one of the nutritional therapists also asserted that nutrition could play a role in assisting the body to recover following chemotherapy.

The CAM practitioners also discussed the use of CAM to treat numerous side effects and symptoms in different settings. Most of the TCM practitioners identified the use of TCM for side effects such as nausea and vomiting and bone marrow suppression. However, one TCM practitioner also pointed to the use of herbal medicine for alopecia, while another highlighted its use for treating pain and fatigue. Another TCM practitioner treated women with breast cancer for relief of menopausal symptoms. According to the same practitioner, acupuncture and herbal medicine can be used to support patients with cancer in the curative setting "control of local swelling post-operatively" and in the palliative setting for "nausea and vomiting".

Relaxation therapies such as reflexology were also perceived to have a role in managing different symptoms and side effects; reflexology was beneficial for the treatment of fatigue, low energy and sleeplessness according to one of the reflexologists. It was also claimed that reflexology can alleviate other symptoms such as nausea and constipation.

A duty of one participant was to explain the different therapies that were available to patients attending the CSC. While acknowledging the benefits of reflexology in terms of relaxation and improved energy levels, this participant asserted that they were cautious about ascribing any claims to the therapy: "all we say is 'look, at times people can come back and say they feel better, or they have more energy or they feel better in themselves'". According to another reflexologist, in her experience lymphoedema in women with breast cancer can also improve with reflexology. Homeopathy was also employed to "support the system" and "build up their own immune system" while patients were receiving conventional treatment. Referring to treatment of patients in the hospice, one homeopath was keen to point out that homeopathy is appropriate for patients at all stages of cancer including those who are dying.

While there appeared to be little doubt among the participants that various CAM therapies were effective for symptom/side effect management, some difference of opinion emerged in relation to certain CAM therapies employed. 
All of the CAM practitioners discussed the value of their respective CAM therapies for symptom/side effect management. However, some held considerably different views regarding the safety of certain CAM therapies which were practised and valued by other practitioners. One participant was "wary" about the use of antioxidants and of boosting the immune system fearing they may be counterproductive.

... antioxidants ... still [not clear] whether they're a good thing or a bad thing ... because is the ... tumour using them ... to protect themselves? (Nutritional Therapist)

Having practised reflexology in the past, one of the TCM practitioners expressed some concern about this therapy "because you're stimulating all these areas and you don't really know what you're doing, really, whereas the acupuncture is really pin point". Conversely, one of the reflexologists had some reservations about the use of massage unless the practitioners were "qualified or dealing with cancer patients a lot". According to one of the massage therapists, acupuncture may not be appropriate for patients who were undergoing chemotherapy due to their immunosuppressed state. This participant was also somewhat equivocal about the use of "herbs even vitamins"; acknowledging that there are practitioners who can use them to complement conventional treatment, she concluded that one would have to be "very iffy around them". In addition, most (but not all) of the TCM practitioners appeared to favour the use of acupuncture over herbal medicine perceiving that there was less risk involved with this approach.

I'd always use acupuncture because its to play it safer, it's incredibly effective anyway, so you can avoid and you're going to have no interactions with anything else anyone else is doing, so it's really, really safe (TCM)

Clearly then, symptom/side effect management was one of the key reasons identified by CAM practitioners for CAM use when supporting patients with cancer. In addition to symptom/side effect management, participants also described the supportive role of CAM in terms of psychological support and this is now discussed.

\subsection{Psychological support}

According to the participants, the supportive role of CAM was also concerned with the provision of psychological support to patients with cancer. In particular, it was considered essential to address patients' psychological concerns given the fear associated with cancer. The use of different CAM approaches was discussed with a view to facilitating patients to express their fears, rebuild confidence and regain a sense of control. The importance of time and space was emphasised. Moreover, there was a sense that up until recently psychological support has not been to the forefront of care for cancer patients in the conventional setting. Some of the participants perceived that patients who received greater psychological support were more likely to have improved outcomes with respect to the cancer itself.

Participants discussed the importance of enabling patients to express their "inner fears" given the fear that surrounds a cancer diagnosis.

... people feel fragile, feel vulnerable, where their questions are about the whole meaning or coping or dealing with fear (Counsellor) 
One homeopath indicated that the emphasis in the conventional setting has traditionally been on the physical dimensions of cancer with less focus on psychological outcomes. Another participant suggested that while chemotherapy works to eliminate the cancer, CAM focuses on the psychological dimensions of the illness and "acknowledges" patients in a way that no longer occurs in the conventional setting. This development was blamed on "the system".

... CAM can work to kind of heal the psychological aspects of the soul, the spirit ... that was all part of our training (health professional) but its just gone out the window ... so I think in theory you all believe in it, the system doesn't allow for that ... (Massage Therapist)

One of the participants (cancer survivor) alluded to the fact that the CSCs are now redressing the balance by placing a priority on psychological support. According to this participant, prior to the CSCs there was "no support" for patients who had just completed treatment whereas patients received support from the nurses and fellow patients while on treatment. This recent focus on psychological care was also noted by one of the CSC-based practitioners who spoke of a patient describing her (the patient's) experience at a CSC three years previously as life-saving.

Acknowledging the fear that surrounds a cancer diagnosis, CAM practitioners endeavoured to attend to the psychological impact of cancer on patients with a view to facilitating expression of fear. One of the homeopaths spoke about the importance of "getting people emotionally stronger" while another used an initiative developed by Dr Rosy Daniel entitled "The Health Creation Programme" to assist patients to set priorities when "shell shocked" on receiving their diagnosis at the outset. While acknowledging that it is not counselling, one of the reflexologists suggested that reflexology may encourage patients to "open up" to a greater extent by removing any pressure to engage in a discussion while simultaneously facilitating a supportive environment should they wish to do so.

Certain CAM therapies were also considered beneficial in terms of helping patients to rebuild their confidence. According to one of the participants, hydrotherapy was very beneficial for patients in this way. Having observed the use of this treatment in the hospice setting, this participant determined that the water provided a degree of "freedom" which assisted patients who may feel "very restricted, very tight". The same participant also found that yoga released patients from being "stuck and protective" following surgery. According to another participant, in her experience "touch therapies" were particularly valuable in the terms of encouraging women who were dealing with "altered body image" to embrace themselves again.

... it can be very helpful in actually in terms of coming to terms with that and embracing, literally embracing themselves (Massage Therapist)

Of note, other participants highlighted the value of reflexology in the context of "altered body image". The impression was that all patients could benefit from touch therapies including those who were not feeling confident due to a change in their body image. One of the reflexologists contended that this therapy may be a more appropriate than massage for certain patients such as those post-mastectomy for this reason.

The value of CAM in assisting patients to regain a sense of control was highlighted across the different specialties. 
... everybody's doing things for them ... now 'this is a choice that I'm making myself, because I can do something to help myself' (Reflexologist)

According to one of the CSC-based practitioners, the approach in the CSCs was to point out the different services available thereby enabling patients to take control and choose therapies on the basis of their needs. One of the massage therapists endeavoured to give patients a choice in choosing the aromatherapy oils before a massage.

In addition, participants across the different specialties discussed the importance of "time and space" in the context of providing psychological support to patients with cancer. According to one of the TCM practitioners, patients "appreciate the time that they are given, to be listened to" while another noted that "in TCM and indeed most CAM therapies they are treated as a unique individual" and are given "plenty of time to tell their story and to ask questions". One of the homeopaths stated that she would spend one hour with each patient and even two hours with a new patient in order to undertake a complete history from childhood onward while one of the reflexologists stated that she endeavored to provide time and space to facilitate patients to express their emotions. Similarly, the importance of "time and space" was also highlighted by a phytobiophysics practitioner. This practitioner also practised reiki, a therapy which was identified as being particularly valuable for patients "own healing within" regardless of their prognosis. There was a sense that a lack of time in the conventional setting precluded patients from discussing their fears about the illness.

\section{... their doctor is not getting the time to really sit down and talk to them about their fears (TCM)}

According to another TCM practitioner, conventional practitioners are "shooting themselves in the foot" by not allocating time for patients to discuss their fears. This practitioner highlighted the dissatisfaction resulting from this situation as another "negative thing" for patients. Similarly, one of the massage therapists, stated that nurses and doctors are so busy in hospitals in the present day that caring albeit time-consuming measures such as "long bed baths" are no longer undertaken and patients are being "lost in the whole system".

Addressing patients' psychological concerns was seen to have benefits which extended beyond the immediate concerns to encompass the actual disease itself. According to one of the TCM practitioners, while acupuncture given for emotional distress may not shrink the actual tumour, it may arrest further progression by containing the patient's stress.

... because the cellular division doesn't get more intensified through, through you know stress, I don't know if stress and cancer how much they've related it in Western medicine but we see a relationship (TCM)

Similarly, one of the participants considered the potential impact of psychological support on the immune system after watching a TV programme which demonstrated "an effect biochemically" in another illness. For two of the homeopaths, improved outcomes were more evident in patients who were robust from a psychological, physical and social perspective. While participants placed most emphasis on supporting patients symptomatically and psychologically, some also the highlighted the importance of providing mental and spiritual support to patients. 


\subsection{Mental concentration and spiritual support}

A holistic approach to care also required that patients' "mental" and spiritual needs were attended to.

The homeopath ... treats the whole person this means on an emotional, mental, physical and spiritual level (Homeopath)

One of the TCM practitioners contrasted their approach to care with conventional practice where she contended that the focus was only on surgically removing the tumour while there was less attention being paid to the "internal, mental, emotional". Some of the participants highlighted the value of certain therapies in terms of attaining mental clarity. It was asserted that acupuncture can improve concentration and the ability to prioritise tasks. Similarly, one of the reflexologists claimed that reflexology assisted patients to prioritise; "it clears the wool from the brain". Yoga required patients to concentrate on breathing and movement during the class so "they are not as caught up in their thoughts" according to one of the Massage Therapists.

The concepts of time and space were again considered in relation to spiritual support. During reflexology sessions, one of the reflexologists endeavored to allow "time and space" to facilitate spiritual reflection. One of the CSC-based counsellors contended that a "holistic complementary service" was "integral to the cancer journey".

because I have yet to meet somebody who ... who just wants to know what is happening next and who's able to move on with life ... and it touches into so many other areas of their lives, relationships, communication, goals, sense of meaning, existential questions ... (Counsellor)

A spiritual approach to care was also alluded to by one of the homeopaths who spoke of the importance of viewing cancer as a challenge which could afford an opportunity for patients to make changes to their lives.

As outlined, participants indicated that CAM can provide a supportive role for patients with cancer by utilising a holistic approach to addressing their physical, psychological, mental and spiritual needs. The role of CAM in relation to conventional medicine was also considered and this is now briefly described.

\subsection{Complementary to conventional medicine: Different interpretations}

While it was clear that participants were in agreement that the primary role of CAM was to support patients through their cancer journey, their views regarding the position of CAM with respect to conventional treatment were less cohesive. Essentially, most of the practitioners of relaxation/psychological therapies emphasised their role as one confined to assisting patients as they received their primary treatment in the conventional setting. In essence, they distanced themselves from suggestions that CAM therapies could be an alternative to conventional treatment. Their views differed from those of practitioners of biologically based therapies who considered a broader role for CAM which also incorporated cancer treatment and prevention. Of interest, the term "complementary" was used with respect to both views suggesting that it may have a different meaning for the different groups. 
Practitioners of relaxation/psychological therapies were more inclined to refer to the "complementary" role of CAM in the context of providing assistance to patients as they received conventional treatment and negotiated their way through the cancer journey. In essence, the impression given by practitioners of relaxation/psychological-based therapies was that they were working in harmony with conventional practitioners. That is, conventional practitioners managed the actual disease while they supported the patient through the process.

...because it, cancer is a medical condition; it needs to be worked through the medical field, then yeah we are the complementary one to assist them along that journey (Reflexologist)

According to another participant, the role of CAM in the management of cancer may not be as central as that of conventional treatment; nonetheless, it complements conventional treatment by considering the psychological dimensions thereby facilitating a more holistic approach to care. Some of the participants were also keen to emphasise that the CAM provided in the CSCs was "complementary" in nature as distinct from "alternative".

First of all I consider what I do as complementary and I don't consider it alternative therapy so what I do complements orthodox treatments (Reflexologist)

It was evident then that CSC-based practitioners considered that they worked in harmony with the conventional providers. Consistent with this perspective, there was little to suggest that these participants encouraged patients to consider any treatments outside of those prescribed by their doctors.

When asked about herbal supplements by patients, one such participant stated that she advised patients against taking any biologically based therapies that the conventional practitioners had not prescribed.

I wouldn't recommend, taking any medication that the medical don't know about because you can't be sure of, you know, content or interactions ok, so that would be my standard line (Counsellor)

Another CSC-based practitioner also avoided making any recommendations regarding herbal supplements to patients attending the CSC stating that she was not qualified to do so and that CSC policy precludes the provision of such advice. According to one of the reflexologists, there is a general awareness that some CAM practitioners have been giving advice "which they shouldn't have been" and she advised her reflexology students accordingly.

... 'you don't diagnose, you don't tell people to change their medicine, you don't, you don't go off, that's not your role' (Reflexologist)

Conversely, while practitioners of biologically based therapies also discussed the "complementary" role of CAM, their understanding of the term appeared to include the use of CAM to impact more directly on the cancer itself in terms of treatment and prevention. The role of CAM in cancer treatment was highlighted by the TCM practitioners in particular. According to one of these practitioners, acupuncture and herbal medicine can be used as an adjunct to conventional treatment.

... to aid in tumour reduction itself, potentially reducing the length of time the patient needs to receive radiation and/or chemotherapy (TCM) 
While other TCM practitioners described their use of CAM to primarily support patients rather than to directly treat the cancer, they also pointed to the value of TCM as a treatment in its own right and the benefits of using it in conjunction with conventional treatment. One practitioner highlighted the use of TCM in addition to chemotherapy and radiotherapy in China; however, she did state that her practice was focused more on supporting the patient and that she was not going to "pretend" she was treating the cancer although "it shouldn't be just one way". Similarly, another TCM practitioner maintained that she would be in favour of people using conventional treatment as their "first line" and did not agree with CAM being used as "stand alone therapy" in cancer treatment. Nonetheless, she also underlined the more dominant position of TCM in China whereby Western diagnostic procedures are used but treatment involves the use of herbal medicine and acupuncture.

Ok, in the West we will use ourselves as complementary practitioners but you know in Asia we are stand alone (TCM)

One of the TCM practitioners contended that there was "no infrastructural backup" in Ireland to enable practitioners to treat cancer directly. This being the case, he treated patients primarily for side effects of conventional treatments. Nonetheless, he did express an interest in a system whereby herbal medicine would be offered in a cancer hospital which would allow patients to choose between CAM and conventional treatment.

that they are given a choice between the two (TCM)

The role of diet in controlling cancer was also considered. According to one of the nutritional therapists, addressing conditions such as food intolerances and allergies may release the immune system to deal with other problems such as cancer cell growth. Another participant highlighted the use of TCM in the management of early cancers. However, this participant admitted to adopting a conservative approach to the treatment of patients with cancer due to fear of repercussions if patients were to subsequently develop problems due to interactions with conventional treatment.

... not when they're in treatment, you don't cross over treatments ... we've got to be very wary insurance-wise because you know if something happens you know because you're the, you're the first point of call if there's something wrong (TCM)

One of the nutritional therapists also expressed similar concerns. Mindful of the potential consequences if there was an interaction with conventional treatment, this practitioner avoided giving supplements to patients once they started on conventional treatment.

Given the concerns about interactions with conventional treatment and the potential repercussions, it is not surprising then that most of the practitioners of biologically based therapies expressed an interest in working in collaboration with conventional providers.

... I don't want to take a risk ... of maybe just it's brushing over the medical side and say I go just only complementary but I know that the complementary side of medicine has a huge big place and it's ... not replaceable (Homeopath)

One of the TCM practitioners indicated that some patients with advanced disease opted to use TCM over conventional cancer treatment. While this practitioner spoke of having seen some "incredible results" with TCM alone, she also indicated that she would only treat patients in this way when they had discussed the issue with their oncologists because "you 
know the odd person comes in and it completely helps them but that doesn't mean it's going to do it for everybody."

Other practitioners also indicated that they encouraged patients to remain involved with their conventional practitioners.

... [on] no occasion do we say don't go to a doctor, quite the opposite, a good responsible homeopath, professional homeopath will say look check it out with your GP if you think you have a serious problem a cancer, growth, tumour whatever by all accounts (Homeopath)

... they might initially not tell you that they've decided to drop their conventional treatment, which I would always tell them not to (TCM)

Acknowledging that it is rare, another homeopath also stated that patients sometimes wish to use homeopathy as an alternative to conventional treatment. However, this participant stated that he discourages his patients from adopting this approach, underlining the fact that he wants them to have a "conventional diagnosis" as he does not have the diagnostic equipment necessary for assessing the extent of disease. The legal implications were also acknowledged.

An interest in collaboration was also expressed by others. Another homeopath stated that he would "love" to work with "surgeons and other doctors" who would acknowledge his role as a practitioner who would "strengthen" and "prepare" patients undergoing conventional treatment. The "ideal" for one of the phytobiotherapists was a "medical centre" where both sides would adopt a multidisciplinary approach to patient care. Other participants discussed the concept in terms of integration. For one of the nutritional therapists, integration was "key" and it was important for CAM not to be "completely out on your own" and adopting the notion that conventional medicine is undesirable.

According to one of the massage therapists (also a trained herbalist), an integrated health care system would be "wonderful". However, she was particularly emphatic that such an integrated system should not be based on the notion that complementary therapies were harmless but unlikely to be effective, a concept articulated by some "very intelligent personnel" and "so there needs to be a huge amount of learning".

In addition to cancer treatment, a role for CAM in cancer prevention was also highlighted by certain participants.

According to one of the nutritionists, CAM was there to "complement what orthodox medicine has to offer"; however, prevention was major focus for this practitioner. Referring to those with a family history of breast cancer, it was noted that referring them to a nutritionist may "get them sorted" so that cancer never develops. Other practitioners also highlighted the role of CAM in cancer prevention.

One of the most effective roles that TCM can fulfill is to help re-establish an underlying balance in the individual, and to unravel the complex patterns inherent in the body which can, if left untreated, lead to the development of cancer (TCM)

One of the homeopaths described the use of homeopathy in persons with a family history of cancer "to try and stimulate a vital or innate response in the system that the predisposition could be lessened". 
It is clear then that the term "complementary" had a somewhat different meaning for the different practitioners. Practitioners of relaxation/psychological therapies discussed the "complementary" role of CAM in terms of supporting patients as they coped with the disease and conventional treatment. Conversely, the practitioners of biologically based therapies also considered a role for CAM in the treatment and prevention of cancer. However, the term "complementary" in this context also considered the use of CAM with respect to impacting more directly on the cancer itself in terms of treatment and prevention. In particular, the existence of TCM as a "stand-alone" system was highlighted. However, identifying the limitations of CAM as a single modality treatment, some of the practitioners were not comfortable in using CAM by itself to treat cancer. Moreover, the potential for interaction with conventional treatment also resulted in some practitioners adopting a somewhat cautious position. For these reasons, most of the participants expressed an interest in working in collaboration with conventional medicine alluding to the risks inherent in operating separately. In the absence of such collaboration, it appears likely that many practitioners opted to concentrate on supporting patients through treatment as they considered the limitations of CAM as a primary modality. In addition, there was a perception that the "infrastructure" did not exist in Ireland at this time to facilitate a greater role for CAM in the treatment of cancer.

In summary then, the participants described CAM as providing a supportive role for patients with cancer. Patients were supported using a holistic approach to care according to the participants. That is, there was an emphasis on addressing the physical, psychological, mental and spiritual needs of patients and participants perceived that CAM was complementary to conventional treatment.

\section{Discussion}

Prior to this research, a literature search found no qualitative research specifically addressing the role of CAM in the cancer setting from the perspectives of patients, oncology professionals or CAM practitioners. However, reasons for CAM use and attitudes toward CAM use in the cancer setting have been examined in other studies and these are now discussed in light of the findings of this study.

In this study, women with breast cancer perceived that CAM plays a supportive role for patients with cancer and this is consistent with the findings of international studies which have identified symptom/side effect relief (Cui et al., 2004, Hann et al., 2005, Lengacher et al., 2006, Molassiotis et al., 2006), psychological stress relief (Hann et al., 2005; Henderson \& Donatelle, 2004; Lengacher et al., 2006) and a desire for greater control (Chen et al., 2008; Cui et al., 2004; Hann et al., 2005, Henderson \& Donatelle, 2004,) as the primary reasons for CAM use among women with breast cancer. Importantly, in allowing patients to provide greater detail regarding their experience of CAM therapies and their perceptions of the role of CAM, this study has allowed greater insight into the significance of CAM for patients. More specifically, it is less likely that a patient survey could capture for example the importance of human touch for patients with cancer. The value placed on the CSCs by study participants across the different stakeholder groups is also an important finding as there appears to be a dearth of literature in this particular area.

The descriptions of relaxation therapies in this study resonate with the findings of Billhult \& Dahlberg (2001) and Billhult et al., (2007) regarding the notion that such therapies provide a 
respite from conventional treatment. Billhult et al., (2007) identified five themes following their interviews with ten breast cancer patients who had received massage during conventional treatment. These included distraction from a frightening experience, a change from negative to positive, a sense of relaxation, a reinforcement of caring and a sense of feeling good. While acknowledging that their study was small (n=63), Pruthi et al., (2009) pointed to the likelihood that massage may help patients with breast cancer to relax and feel better overall. Similar to our study, Gottlieb \& Wachala (2007) observed high levels of consumer satisfaction in their critical review of 44 studies of professionally led cancer support groups. This level of satisfaction may be related to feeling happier and more at ease, receiving practical and emotional support and experiencing a sense of comfort and camaraderie (Hoey et al., 2008).

The finding that some patients would welcome a greater emphasis on CAM in the cancer setting is also consistent with Balneaves et al., (2007) study which found that some patients were disappointed by their interactions with conventional providers on the subject of CAM. In addition, these authors noted that women who engaged in a "bringing it all together" decision-making process favoured healthcare that was tailored to them as individuals focusing not only on their cancer but also on their overall wellbeing (p.980). All of these women were prior CAM users and were highly committed to using CAM throughout their cancer journey. While perceiving their cancer as serious but "beatable" with conventional treatment, these women also believed that CAM was essential to enhancing their physical, psychosocial and spiritual health and as such they employed a variety of CAM therapies to help them cope with their changed circumstances post treatment and to prevent a recurrence (p.980). However, Balneaves et al., (2007) also noted that a certain cohort of patients whom they identified as the "playing it safe group" appeared to be less committed to incorporating oral CAM therapies into their overall treatment plan (p.979) as they were concerned about risks such as potential interactions with conventional treatments, a concern also echoed by some of our study participants.

Undoubtedly, informed by patients' expressed desire for a more holistic and patient-centred approach (Fitch, 2005; Kendall et al., 2006; Liu et al., 2006, Turton \& Cooke, 2000), the Institute of Medicine (IOM) (2007) issued a report designed to address the needs of the "whole" person with cancer. According to the report, all cancer care should enable the provision of appropriate psychosocial support by facilitating effective communication between patients and health professionals and by identifying each patient's psychosocial health needs. Moreover, where the need existed, patients should be linked up with psychosocial services and their physical and psychosocial care should be co-ordinated. All cancer care should endeavor to engage and support patients in managing their disease and treatment and finally, it would be necessary to ensure systematic follow-up, re-evaluation, and modification of care as required (IOM 2007). Similarly, a position paper by the European Society of Mastology (EUSOMA) (Baum et al., 2006) has identified the importance of providing psychosocial and spiritual support to women with breast cancer.

With regard to oncology professionals' perceptions of the role of CAM in the cancer setting, the results of this study are broadly reflective of international studies which have explored oncology professionals' attitudes toward CAM use in general among their patients. In particular, for the most part, there is consistency regarding oncology professionals' response 
to and support for relaxation/psychological therapies (Bourgeault, 1996; Cindy Wang \& Yates, 2006; Hessig et al., 2004; Newell \& Sanson-Fisher, 2000; Risberg et al., 2004; Roberts et al., 2005; Salmenperä et al., 2003; Tovey \& Broom, 2007) versus their response to and concerns regarding biologically based therapies (Bourgeault, 1996; Cindy Wang \& Yates, 2006; Hyodo et al., 2003; Newell \& Sanson-Fisher, 2000; Salmenperä et al., 2003). However, in a more recent study (Zanini et al., 2008), approximately one fifth of oncology nurses were interested in attending training courses about TCM while almost one third were interested in training courses on homeopathy. Those interested in attending courses on progressive relaxation and massage was approaching 50\% (Zanini et al., 2008). According to Fitch et al., (1999), without exception, oncology nurses endorsed the notion that patients have a right to information, that information is essential for decision-making and that ultimately decisions concerning health are up to the individual. As such, these nurses envisioned their role as one concerned with providing information, facilitating access to information and assisting patients to filter the information acquired. Moreover, they expressed an interest in engaging patients in discussions about CAM rather than avoiding the subject.

As noted above, a new finding from this study concerns oncology professionals' perceptions of the CSCs. It is also interesting to note the challenges faced by oncology professionals who endeavour to achieve a balance between supporting patients who may wish to avail of CAM therapies that they (oncology professionals) have concerns about whilst simultaneously seeking to ensure that patients avoid harm from such therapies.

Literature on CAM practitioners' perceptions of the role of CAM in the cancer setting is sparse; however, one study (Gray et al., 1999), pointed to CAM practitioners' interest in playing a role in caring for patients with cancer. In addition, CAM practitioners consider that there is strong or very strong evidence to support various CAM therapies in cancer treatment and/or symptom/side effect management (Lee et al., 2009). According to Mackereth et al., (2009), factors influencing individuals to work as complementary therapists in the cancer/palliative care settings included the desire to provide individualised treatment while adopting a patient-centered caring approach.

The research literature on CAM practitioners in general (including but not exclusive to the area of cancer) points to certain trends: for the most part, CAM practitioners articulate a general sense of respect and goodwill toward conventional practitioners (Barrett et al., 2004), desire closer communication (Klimenko et al., 2006, Klimenko et al., 2007) and greater collaboration with mainstream medicine (Barrett et al., 2004, Ben-Arye et al., 2007). Of note, Barrett et al., (2004) also pointed to practitioners' contentions that major differences and barriers existed between CAM and mainstream medicine. Moreover, they indicated concern about accessibility issues in healthcare and asserted that attitudes and beliefs were often greater barriers to integration than economic or scientific issues. This study has also highlighted significantly different views between oncology professionals and CAM practitioners particularly with respect to the use of biologically based therapies while patients are receiving conventional treatment.

Although integrative healthcare (IHC) has developed in some settings (White 2002), the degree of integration may be less than that envisioned due to the continued existence of dominant biomedical patterns of professional interaction (Hollenberg, 2006; Soklaridis et al., 
2009). The purported limited evidence base for CAM therapies (Ernst, 2009; Gerber et al., 2006) is likely to be a major contributing factor in this context; moreover, given the challenges faced by CAM practitioners in the design and conduct of CAM research in the general (Ben-Arye et al., 2004; Coulter, 2007) and oncology settings (Gerhard et al., 2004, Richardson et al., 1998) it is unlikely that the problem of CAM research will be easily resolved. However, Vickers (2001) argues that there are no good reasons to suggest that evidence-based medicine (EBM) and CAM are incompatible as the former provides CAM with an opportunity to find an "appropriate and just place in health care" (p.1). This assumes, however, that CAM practitioners have expertise in research methods which according to a study $(n=65)$ by Hadley et al., (2009) the majority do not, given their inadequate training in research methods and evidence-based practice.

Our study has provided some insight into the role of CAM in the cancer setting as perceived by Irish CAM practitioners. The sector is currently undergoing a process of self regulation, a position supported by the Irish Government in 2006 following the launch of a report (National Working Group on the Regulation of Complementary Therapists 2005) which was commissioned to examine regulatory issues in the area. Importantly, this study also reflects the difficulties associated with using the term CAM to describe all practitioners who are not currently working in the conventional setting including those whose perspectives may be more aligned with those of conventional practitioners than with those of CAM practitioners.

\section{Conclusion}

While all three stakeholder groups considered CAM as supportive, perspectives differed among oncology professionals and CAM practitioners regarding the manner in which this was so. In general, there was consistency among all three groups with respect to the supportive nature of relaxation-based therapies and psychological therapies. However, oncology professionals and CAM practitioners' perspectives differed significantly with respect to the role of biologically based therapies in the cancer setting. These converging and diverging perspectives most likely reflect the complexity of the subject whereby CAM encompasses many different approaches, therapies and practitioners. Given this situation, it seems prudent that continued efforts should be made to engage with all patients with cancer with a view to ascertaining their perspectives on CAM and endeavouring to meet their needs where it appears safe to do so. Engaging with patients in this way should ensure that patients are referred to CSCs and/or accredited community-based practitioners for relaxation/psychological therapies should they wish to avail of these therapies. Such an engagement should also facilitate a discussion regarding patients' intentions to consume biologically based therapies while receiving conventional therapy thereby decreasing risks associated with interactions between these treatments and/or adverse effects apart from such interactions.

\section{References}

Attride-Stirling, J. (2001) Thematic networks: an analytic tool for qualitative research. Qualitative Research, Vol. 1, pp. 385-405. 
Barrett, B; Marchand, L; Scheder, J; Appelbaum, D; Plane, M.B; Blustein, J., Maberry, R. \& Capperino, C. (2004) What complementary and alternative medicine practitioners say about health and health care. Ann Fam Med. Vol. 2, No. 3, pp. 253-259.

Balneaves, L.G; Truant, T.L; Kelly, M; Verhoef, M.J. \& Davison, B.J. (2007) Bridging the gap: decision-making processes of women with breast cancer using complementary and alternative medicine (CAM). Support Care Cancer. Vol, 15, No. 8, pp. 973-983.

Baum, M; Cassileth, B.R; Daniel, R; Ernst, E; Filshie, J; Nagel, G.A; Horneber, M; Kohn, M; Lejeune, S; Maher J; Terje R. \& Smith, W.B. (2006) The role of complementary and alternative medicine in the management of early breast cancer: recommendations of the European Society of Mastology (EUSOMA). Eur J Cancer. Vol 42, No. 12, pp. 1711-1714.

Ben-Arye, E; Frenkel, M. \& Margalit, R.S. (2004) Approaching complementary and alternative medicine use in patients with cancer: questions and challenges. J Ambul Care Manage. Vol 27, No. 1, pp. 53-62.

Ben-Arye, E; Scharf M. \& Frenkel M. (2007) How should complementary practitioners and physicians communicate? A cross-sectional study from Israel. J Am Board Fam Med. Vol 20, No. 6, pp. 565-571.

Billhult, A. \& Dahlberg, K. (2001) A meaningful relief from suffering: experiences of massage in cancer care. Cancer Nurs Vol 24, pp. 180-184.

Billhult, A., Stener-Victorin, E. \& Bergbom, I. (2007) The experience of massage during chemotherapy treatment in breast cancer patients. Clin Nurs Res. Vol 16, No. 2, pp. 85-99.

Bourgeault, I. L. (1996) Physicians" attitudes toward patients' use of alternative cancer therapies. Canadian Medical Association Journal, Vol 155, No. 12, pp. 1679-1685.

Chen, Z; Gu, K; Zheng, Y; Zheng, W; Lu, W. \& Shu, X.O. (2008) The use of complementary and alternative medicine among Chinese women with breast cancer. J Altern Complement Med. Vol 14, No. 8, pp, 1049-1055.

Cindy Wang, S.Y. \& Yates, P. (2006) Nurses' responses to people with cancer who use complementary and alternative medicine. Int J Nurs Pract. Vol. 12, No. 5, pp. 288294.

Coulter, I.D. (2007) Evidence-based complementary and alternative medicine: promises and problems. Forsch Komplementmed. Vol 14, No. 2, pp. 102-108.

Cui, Y; Shu, X.O; Gao, Y; Wen, W; Ruan, Z.X; Jin, F. \& Zheng, W. (2004) Use of complementary and alternative medicine by Chinese women with breast cancer. Breast Cancer Res Treat. Vol. 85, No. 3, pp. 263-270.

Department of Health and Children (2006) National Working Group on the Regulation of Complementary Therapists, Report of the National Working Group on the Regulation of Complementary Therapists to the Minister for Health and Children. The Stationary Office, Dublin.

Department of Health and Children (2006) Press Release: Launch of Report of the National Working Group on the Regulation of Complementary Therapists (2006). Available at: http// www.dohc.ie (accessed October 24th 2009).

Ernst, E. (2009) How Much of CAM is Based on Research Evidence? Evid Based Complement Alternat Med. May 21. PMID: 19465405.

Ezzy, D. (2002) Qualitative Analysis: Practice and Innovation. Routledge, London. 
Fitch, M. I. (2005) Needs of patients living with advanced disease. Can Oncol Nurs J. Vol 15, No. 4, pp. 230-242.

Fitch, M.I; Gray, R.E; Greenberg, M; Douglas, M.S; Labrecque, M; Pavlin, P; Gabel, N. \& Freedhoff S. (1999) Oncology nurses' perspectives on unconventional therapies. Cancer Nurs. Vol 22, No. 1, pp. 90-96.

Gerber, B; Scholz, C; Reimer, T; Briese, V. \& Janni, W. (2006) Complementary and alternative therapeutic approaches in patients with early breast cancer: a systematic review. Breast Cancer Research and Treatment, Vol 95, pp. 109-209.

Gerhard, I; Abel, U; Loewe-Mesch, A; Huppmann, S. \& Kuehn, J.J. (2004) Problems of randomized studies in complementary medicine demonstrated in a study on mistletoe treatment of patients with breast cancer. Forsch Komplementarmed Klass Naturheilkd. Vol, 11, No. 3, pp. 150-157.

Gottlieb, B.H. \& Wachala, E.D. (2007) Cancer support groups: a critical review of empirical studies. Psychooncology Vol, 16, No. 5, pp. 379-400.

Gray, R.E; Fitch, M; Saunders, P.R; Wilkinson, A; Ross, C.P; Franssen, E. \& Caverhill K. (1999) Complementary health practitioners' attitudes, practices and knowledge related to women's cancers. Cancer Prev Control. Vol 3, No. 1, pp. 77-82.

Hadley, J; Hassan, I. \& Khan, K.S. (2008) Knowledge and beliefs concerning evidence-based practice amongst complementary and alternative medicine health care practitioners and allied health care professionals: a questionnaire survey. BMC Complement Altern Med. Vol. 23, No. 8:45.

Hann, D; Baker, F; Denniston, M; Entrekin, N. (2005) Long-term breast cancer survivors" use of complementary therapies: perceived impact on recovery and prevention of recurrence. Integr Cancer Ther. Vol. 4, No. 1, pp. 14-20.

Henderson, J.W. \& Donatelle, R.J. (2004) Complementary and alternative medicine use by women after completion of allopathic treatment for breast cancer. Altern Ther Health Med. Vol. 10, No. 1, pp. 52-57.

Hessig, R.E; Arcand, L.L. \& Frost M.H. (2004) The effects of an educational intervention on oncology nurses' attitude, perceived knowledge, and self-reported application of complementary therapies. Oncol Nurs Forum, Vol. 31, No. 1, pp. 71-78.

Hoey, L.M; Leropoli, S.C; White, V.M \& Jefford, M. (2008) Systematic review of peer-support programs for people with cancer. Patient Education and Counseling, Vol. 70, No. 3, pp. 315-337.

Hollenberg, D. (2006) Uncharted ground: patterns of professional interaction among complementary/alternative and biomedical practitioners in integrative health care settings. Soc Sci Med. Vol. 62, No. 3, pp. 731-744.

Hyodo, I; Eguchi, K; Nishina, T; Endo, H; Tanimizu, M; Mikami, I; Takashima, S. \& Imanishi, J. (2003) Perceptions and attitudes of clinical oncologists on complementary and alternative medicine: a nationwide survey in Japan. Cancer, Vol 97, No. 11, pp. 2861-2868.

Institute of Medicine (2007) Cancer care for the whole patient: meeting psychosocial health needs. Available from: http://www.iom.edu. (Accessed April 22nd 2010).

Kendall, M; Boyd, K; Campbell, C; Cormie, P; Fife, S; Thomas, K; Weller, D. \& Murray, S.A. (2006) How do people with cancer wish to be cared for in primary care? Serial discussion groups of patients and carers. Fam Practice, Vol. 23, No. 6, pp. 644-650. 
Klimenko, E. \& Julliard, K. (2007) Communication between CAM and mainstream medicine: Delphi panel perspectives. Complement Ther Clin Pract. Vol 13, No. 1, pp. 46-52.

Klimenko, E; Julliard, K; Lu, S.H \& Song, H. (2006) Models of health: a survey of practitioners. Complement Ther Clin Pract. Vol. 12, No. 4, pp. 258-267.

Lee, C.D; Zia, F; Olaku, O; Michie, J. \& White, J.D. (2009) Survey of complementary and alternative medicine practitioners regarding cancer management and research. J Soc Integr Oncol. Vol. 17, No. 1, 26-34.

Lengacher, C.A; Bennett, M.P; Kip, K.E; Gonzalez, L; Jacobsen, P. \& Cox, C.E. (2006) Relief of symptoms, side effects, and psychological distress through use of complementary and alternative medicine in women with breast cancer. Oncol Nurs Forum, Vol. 33, No. 1, pp. 97-104.

Liamputtong, P. \& Ezzy, D. (2005) Qualitative Research Methods. Oxford University Press, South Melbourne.

Liu, J.E; Mok, E. \& Wong, T. (2006) Caring in nursing: investigating the meaning of caring from the perspective of cancer patients in Beijing, China. J Clin Nurs. Vol. 15, No. 2, pp. 188-196.

Mackereth, P; Carter, A; Parkin, S; Stringer, J; Roberts, D; Todd, C; Long, A. \& Caress, A. (2009b) Complementary therapists' motivation to work in cancer/supportive and palliative care: a multi-centre case study. Complement Ther Clin Pract. Vol. 15, No. 3, pp. 161-165.

Molassiotis, A; Scott, J.A; Kearney, N; Pud, D; Magri, M; Selvekerova, S; Bruyns, I; FernadezOrtega, P; Panteli, V; Margulies, A; Gudmundsdottir, G; Milovics, L; Ozden, G; Platin, N. \& Patiraki, E. (2006) Complementary and alternative medicine use in breast cancer patients in Europe. Support Care Cancer, Vol. 14, No. 3, pp. 260-267.

National Working Group on the Regulation of Complementary Therapists, Report of the National Working Group on the Regulation of Complementary Therapists to the Minister for Health and Children. The Stationary Office, Dublin (2005).

Newell, S. \& Sanson-Fisher, R.W. (2000) Australian oncologists' self-reported knowledge and attitudes about nontraditional therapies used by cancer patients. Med J Aust. Vol. 172, pp. 110-113.

Pruthi, S; Degnim, A.C; Bauer, B.A; DePompolo, R.W. \& Nayar, V. (2009) Value of massage therapy for patients in a breast clinic. Clin J Oncol Nurs. Vol. 13, No. 4, 422-425.

Richardson, M.A; Post-White, J; Singletary, S.E. \& Justice, B. (1998) Recruitment for complementary/alternative medicine trials: who participates after breast cancer. Ann Behav Med. Vol. 20, No. 3, pp. 190-198.

Risberg, T; Kolstad, A; Bremnes, Y; Holte, H; Wist, E.A; Mella, O; Klepp, O; Wilsgaard, T. \& Cassileth, B.R. (2004) Knowledge of and attitudes toward complementary and alternative therapies: a national multicentre study of oncology professionals in Norway. European Journal of Cancer, Vol. 40, No. 4, pp. 529-535.

Roberts, C.S; Baker, F; Hann, D; Runfola, J; Witt, C; McDonald, J; Livingston, M.L; Ruiterman, J; Ampela, R; Kaw, O.C. \& Blanchard, C. (2005) Patient-physician communication regarding use of complementary therapies during cancer treatment. J Psychosoc Oncol. Vol. 23, No. 4, 35-60.

Salmenperä, L; Suominen, T. \& Vertio, H. (2003) Physicians' attitudes towards the use of complementary therapies (CTs) by cancer patients in Finland. Eur J Cancer Care (Engl). Vol. 12, No. 4, pp. 358-364. 
Soklaridis, S; Kelner, M; Love, R.L. \& Cassidy, J.D. (2009) Integrative health care in a hospital setting: communication patterns between CAM and biomedical practitioners. J Interprof Care, Vol. 23, No. 6, pp. 655-667.

Tovey, P. \& Broom, A. (2007) Oncologists' and specialist cancer nurses' approaches to complementary and alternative medicine and their impact on patient action. Soc Sci Med. Vol. 64, No. 12, pp. 2550-2564.

Turton, P. \& Cooke, H. (2000) Meeting the needs of people with cancer for support and selfmanagement. Complement Ther Nurs Midwifery, Vol. 6, No. 3, pp. 130-137.

White, J.D. (2002) The National Cancer Institute's perspective and agenda for promoting awareness and research on alternative therapies for cancer. J Altern Complement Med. Vol. 8, No. 5, pp. 545-550.

Zanini, A; Quattrin, R; Goi, D; Frassinelli, B; Panariti, M; Carpanelli, I. \& Brusaferro, S. (2008) Italian oncology nurses' knowledge of complementary and alternative therapies. JAN, Vol. 62, No. 4, pp. 451-456. 


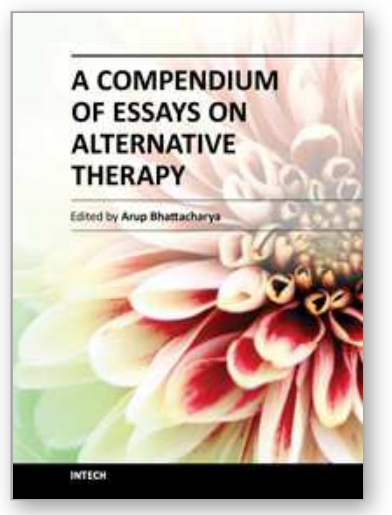

\author{
A Compendium of Essays on Alternative Therapy \\ Edited by Dr. Arup Bhattacharya
}

ISBN 978-953-307-863-2

Hard cover, 302 pages

Publisher InTech

Published online 20, January, 2012

Published in print edition January, 2012

A Compendium of Essays on Alternative Therapy is aimed at both conventional and alternate therapy practitioners, besides serving as an educational tool for students and lay persons on the progress made in the field. While this resource is not all-inclusive, it does reflect the current theories from different international experts in the field. This will hopefully stimulate more research initiatives, funding, and critical insight in the already increasing demand for alternate therapies that has been evidenced worldwide.

\title{
How to reference
}

In order to correctly reference this scholarly work, feel free to copy and paste the following:

Patricia Fox, Michelle Butler and Barbara Coughlan (2012). The Role of CAM (Complementary and Alternative Medicine): The Different Perspectives of Patients, Oncology Professionals and CAM Practitioners, A Compendium of Essays on Alternative Therapy, Dr. Arup Bhattacharya (Ed.), ISBN: 978-953-307-863-2, InTech, Available from: http://www.intechopen.com/books/a-compendium-of-essays-on-alternativetherapy/the-role-of-cam-complementary-and-alternative-medicine-the-different-perspectives-of-patientsoncolo

\section{INTECH}

open science | open minds

\section{InTech Europe}

University Campus STeP Ri Slavka Krautzeka 83/A 51000 Rijeka, Croatia Phone: +385 (51) 770447 Fax: +385 (51) 686166 www.intechopen.com

\section{InTech China}

Unit 405, Office Block, Hotel Equatorial Shanghai No.65, Yan An Road (West), Shanghai, 200040, China 中国上海市延安西路65号上海国际贵都大饭店办公楼405单元 Phone: +86-21-62489820

Fax: +86-21-62489821 
(C) 2012 The Author(s). Licensee IntechOpen. This is an open access article distributed under the terms of the Creative Commons Attribution 3.0 License, which permits unrestricted use, distribution, and reproduction in any medium, provided the original work is properly cited. 